\title{
Variation of optical parameters of multilayer structures with thin silicon layers at laser annealing
}

\author{
O.B. Okhrimenko \\ V. Lashkaryov Institute of Semiconductor Physics, NAS of Ukraine \\ 41, prospect Nauky, 03028 Kyiv, Ukraine \\ Phone: 38(044) 525-62-61; fax: 38(044) 525-83-42; e-mail: konakova@isp.kiev.ua
}

\begin{abstract}
The experimental data on Raman scattering (RS) and optical absorption in structures with thin silicon layers on various substrates, as well as in multilayer quartz $/ \mathrm{Si} / \mathrm{SiO}_{2}, \mathrm{SiC} / \mathrm{Si} / \mathrm{SiO}_{2}$ and glass $/ \mathrm{Si}_{3} \mathrm{~N}_{4} / \mathrm{Si} / \mathrm{SiO}_{2}$ structures, are summarized. It is shown that laser annealing on the above structures leads to changes in spectra of RS and optical transmission that can be explained within the critical action model. The value of critical action of laser radiation is determined for the structures studied.
\end{abstract}

Keywords: laser annealing, optical transmission, Raman scattering, thin silicon layers.

Manuscript received 16.01.14; revised version received 23.04.14; accepted for publication 12.06.14; published online 30.06.14.

\section{Introduction}

As the electronic devices are becoming smaller and ICs are becoming more complicated, local pulse treatment of them acquires increasing importance. It enables to modify certain micro-areas without affecting neighboring sections and lower layers. Application of laser annealing makes it possible to prepare polycrystalline silicon (polySi) films which is promising for use in thin-film transistors, liquid-crystal displays, sensors and solar cells because of recrystallization of amorphous $\mathrm{Si}(\alpha-\mathrm{Si})$ films [1]. Besides, laser annealing enables to modify electrophysical and optical parameters of semiconductors as well as their crystalline and defect structure $[2,3]$.

In the course of laser annealing of $\alpha-\mathrm{Si}$ or poly-Si layers deposited onto a single crystalline $\mathrm{Si}$ substrate, their homoepitaxial recrystallization occurs $[1,4]$. Such processes may help to obtain the most efficient presentday cascade solar cells with the structure of $\alpha$-Si-poly$\mathrm{Si}$ structure. Laser radiation is also used for annealing of structural defects in semiconductor layers and improvement of silicon surface and, correspondingly, the "silicon-oxide-metal" interfaces when producing ICs
[5]. A promising area of laser radiation application is restructuring of $\alpha$-Si layers (deposited onto a dielectric substrate) to a polycrystalline state. This technology enables to obtain silicon layers with high mobility of charge carriers and is promising in production of panels for solar power engineering, IR detectors and display panels, as well as micro- and nanoeletronic devices.

Of special interest is a possibility of modifying the properties of multilayer systems by laser annealing. In this case, it is possible to apply selective annealing of separate layers in a multilayer composition by selecting appropriate wavelength, power and focusing of laser radiation which cannot be realized at traditional thermal annealing [6]. So investigation of the effect of laser annealing on structures with thin $(\sim 0.1 \mu \mathrm{m})$ silicon layers is of particular interest: in such systems the properties of silicon film can be rather easily modified by laser annealing.

This work summarizes the results of a cycle of investigations on the effect of restructuring of silicon films on various substrates (as well as in multilayer quartz $/ \mathrm{Si} / \mathrm{SiO}_{2}, \quad \mathrm{SiC} / \mathrm{Si} / \mathrm{SiO}_{2}$ and glass $/ \mathrm{Si}_{3} \mathrm{~N}_{4} / \mathrm{Si} / \mathrm{SiO}_{2}$ structures) caused by laser annealing on the optical parameters of such structures. 


\section{Specimens and measurement procedure}

The specimens under investigation were silicon films deposited onto dielectric and semiconductor substrates as well as those in the quartz/ $\mathrm{Si} / \mathrm{SiO}_{2}, \mathrm{SiC} / \mathrm{Si} / \mathrm{SiO}_{2}$ and glass $/ \mathrm{Si}_{3} \mathrm{~N}_{4} / \mathrm{Si} / \mathrm{SiO}_{2}$ structures. The substrates were glass, quartz, high- and low-resistance silicon carbide. The thickness of $\mathrm{SiC}$ substrate was $\sim 450 \mu \mathrm{m}$, while those of $\mathrm{Si}_{3} \mathrm{~N}_{4}$, silicon and silicon dioxide layers were 0.15 $0.25 \mu \mathrm{m}, 0.8-1.0 \mu \mathrm{m}$ and $0.1-0.2 \mu \mathrm{m}$, respectively.

Laser annealing was made using a multi-purpose laser setup for semiconductor processing LIMO 100532/1064-U (LIMO-Lissotschenko Mikrooptik GmbH, Germany) with an Nd:YAG laser (wavelength $\lambda=$ $532 \mathrm{~nm}$ ) [7]. The $\alpha$-Si film was deposited using a setup for electron-beam deposition BY-2M, with concurrent photometric control of film thickness. The thickness of $\alpha$ Si film was $1 \mu \mathrm{m}$ [7].

The Raman scattering (RS) spectra were excited using an $\mathrm{Ar}-\mathrm{Kr}$ laser $\left(\lambda_{\mathrm{ex}}=488 \mathrm{~nm}\right)$. The power of exciting laser radiation was chosen in the $0.2-1.5 \mathrm{~mW}$ range to prevent overheating and laser annealing in the course of measurements. Structural perfection of the Si layer before and after laser annealing was studied with X-ray diffractometry (XRD) using a setup Philips X'Pert-MRD $\left(\mathrm{Cu}_{K \alpha}=0.15418 \mathrm{~nm}\right)$. The absorption spectra of the specimens were taken in the $350-800 \mathrm{~nm}$ range at room temperature busing a setup SPECORD UV VIS.

\section{Experimental results and discussion}

Investigations of absorption spectra in the quartz/Si, glass $/ \mathrm{Si}$ and quartz/ $\mathrm{Si} / \mathrm{SiO}_{2}$ structures [8-10] showed that laser annealing at laser radiation power of 40-80 W leads to shifting of silicon film absorption edge towards shorter wavelengths. The maximal shift $(\sim 0.5 \mathrm{eV})$ was observed for the quartz/Si structure (Fig. 1), while those for the glass $/ \mathrm{Si}$ and quartz $/ \mathrm{Si} / \mathrm{SiO}_{2}$ structures was $\sim 0.1 \mathrm{eV}$.

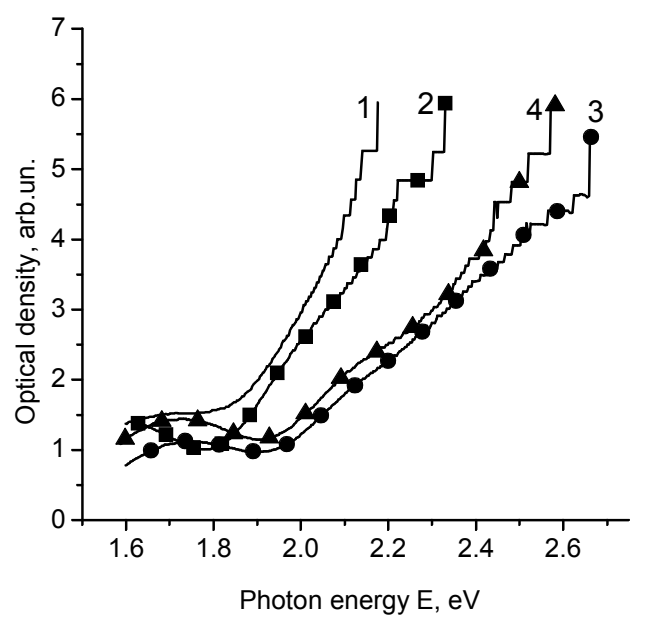

Fig. 1. Absorption spectra of the quartz/Si structure before (curve 1) and after laser annealing (curves 2-4). Laser radiation power: $2-40 \mathrm{~W}, 3-60 \mathrm{~W}, 4-80 \mathrm{~W}$ [8].
It should be noted that laser annealing by $20 \mathrm{~W}$ radiation does not lead to any changes in absorption spectra of the structures under investigation. If the laser radiation power was of $50-70 \mathrm{~W}$, then the structures under investigation demonstrated increase of transmission coefficient in the silicon film (as compared with the initial structure) after laser annealing [8-10].

For all structures under investigation, a general trend exists, namely, their transmission coefficients grow as the laser radiation power increases. However, the transmission spectra of silicon film in the glass/Si structure demonstrate an extra feature: they have an additional band with a maximum near $2.7 \mathrm{eV}(450 \mathrm{~nm})$ whose position depends on the laser radiation power (see Fig. 2a). A growth of laser radiation power to $50 \mathrm{~W}$ results in about twice transmission coefficient increase for the glass/Si structure near $450 \mathrm{~nm}$. Further growth of laser radiation power to $80 \mathrm{~W}$ leads to graceful decrease of the transmission coefficient maximum, practically to the initial value (see Fig. 2b).
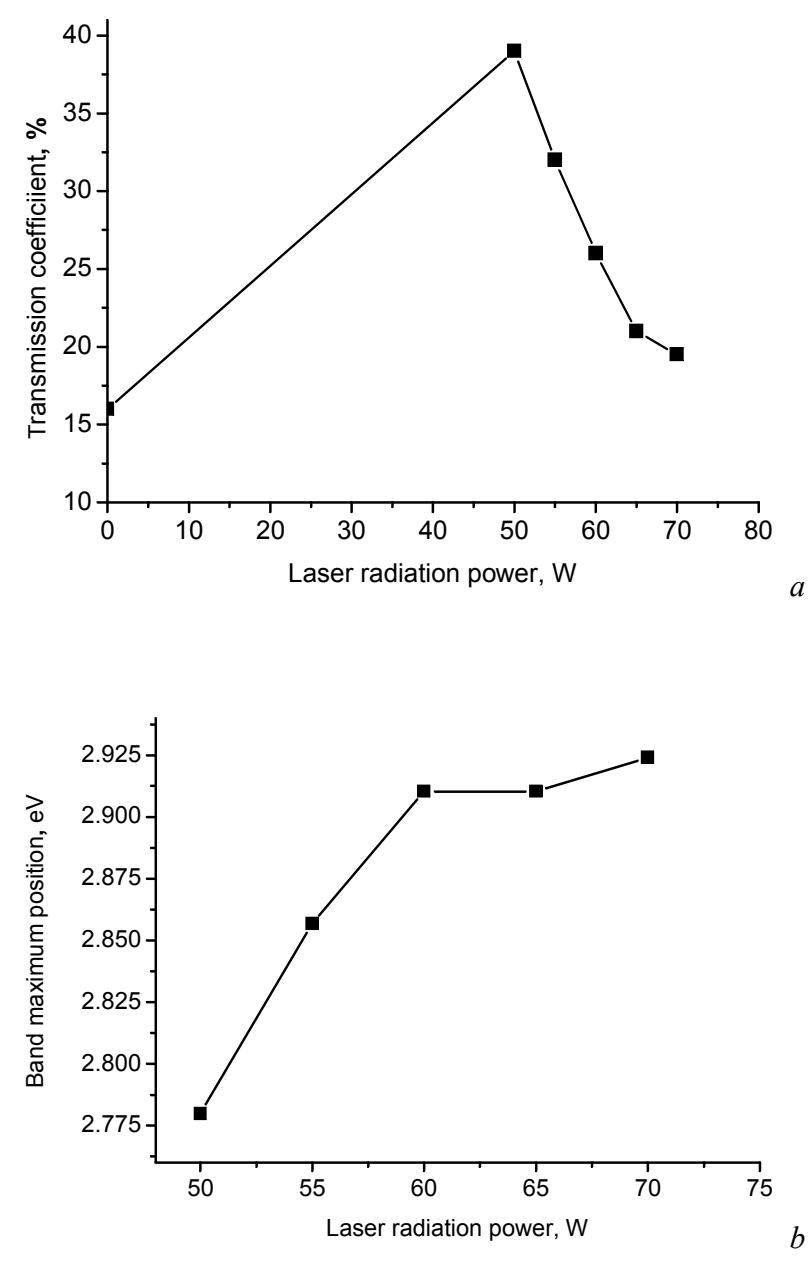

Fig. 2. Transmission coefficient $(a)$ and position of transmission band maximum near $450 \mathrm{~nm}(2.7 \mathrm{eV})(b)$ as functions of laser radiation power for silicon film (glass $/ \mathrm{Si}$ structure) [10]. 
As the laser radiation power is increased to $40 \mathrm{~W}$, then one can also observe absorption edge shifting in silicon film towards shorter wavelengths by $\sim 30 \mathrm{~nm}$. Further growth of laser radiation power to $60 \mathrm{~W}$ promotes increase of absorption edge shift for the specimen under investigation towards shorter wavelengths by $\sim 100 \mathrm{~nm}$ as compared with that of the initial specimen. At laser radiation power of $\sim 80 \mathrm{~W}$, the absorption edge of silicon film shifts insignificantly towards longer wavelengths. At the wavelength range of $300-850 \mathrm{~nm}$, the quartz substrate is transparent. The experiment showed that laser annealing does not lead to changes in absorption spectrum of the quartz substrate. Therefore, shifting of absorption edge in the quartz/Si structure towards shorter wavelengths is due to changes occurring in the silicon film. The observed absorption edge shifting in the spectra of the specimens under investigation correlates with the data given in [4], where it was shown that laser action on thin $\mathrm{Si}$ films at $\mathrm{SiO}_{2}$ surface leads to similar effect because of silicon recrystallization.

Since absorption spectra of a composite structure are integrated quantity, the biggest contribution into absorption spectrum comes from a layer with the maximal absorption coefficient. For the quartz/Si $/ \mathrm{SiO}_{2}$ and $\mathrm{SiC} / \mathrm{Si} / \mathrm{SiO}_{2}$ structures, such an element in the region of $1.5-3 \mathrm{eV}(400-800 \mathrm{~nm})$ is $\mathrm{Si}$ layer. Absorption in silicon carbide substrate in that spectral region is small. A layer-by-layer deposition of $\mathrm{Si} / \mathrm{SiO}_{2}$ structure onto silicon carbide leads to absorption edge smearing. Investigation of the effect of laser annealing on silicon carbide substrate showed that laser annealing does not lead to shifting of intrinsic absorption edge and appearance of additional bands in the absorption spectrum. So, one can conclude that changes in transmission spectrum of the specimen under investigation are due to processes proceeding at the quartz $/ \mathrm{Si} / \mathrm{SiO}_{2}$ and $\mathrm{SiC} / \mathrm{Si} / \mathrm{SiO}_{2}$ interfaces as well as immediately in the $\mathrm{Si} / \mathrm{SiO}_{2}$ layers. Growth of laser radiation power to $40 \mathrm{~W}$ has a small effect on silicon film transparency. Further increase of laser radiation power to $60 \mathrm{~W}$ results in reduction of absorption (i.e., increase of transparency) in the specimen studied in the region of 1.5-3 eV (400-800 nm). However, as the laser radiation power is increased to $80 \mathrm{~W}$, a growth of absorption is observed in the spectral range under investigation.

The increase of transmission coefficients for the quartz/Si, glass $/ \mathrm{Si}$, quartz $/ \mathrm{Si} / \mathrm{SiO}_{2}$ and $\mathrm{SiC} / \mathrm{Si} / \mathrm{SiO}_{2}$ structures that occurs after laser annealing correlates with the data given in [4] where increase of transmission coefficient in thin silicon films resulting from laser annealing was observed too. In [4] that effect was explained by the phase transition from $\alpha$-Si to poly-Si that appeared due to laser annealing. An additional argument that in our case silicon film recrystallization under laser annealing can also occur is shifting of absorption edge in the quartz/Si structure towards shorter wavelengths (Fig. 1) that correlates with the results of [4].
Additional information on processes of silicon films recrystallization under laser annealing can be obtained from analysis of RS spectra. Figure 3 presents RS spectra of the quartz/Si structures, both initial (Fig. 3, curve 1) and those after action of laser radiation of various power (Fig. 3, curves 2 and 3) [11]. One can see that the RS spectra of the initial specimen have a broad band in the region of $480 \mathrm{~cm}^{-1}$ that is related to $\alpha-\mathrm{Si}$ $[1,4]$. After laser annealing, a band $\sim 520 \mathrm{~cm}^{-1}$ appears in the RS spectrum of the quartz/Si structure. According to $[1,4]$, it is related to light scattering from TO phonons in silicon nanocrystallites and is due to the quantum confinement effect that is a sign of phase transition from $\alpha-\mathrm{Si}$ to nano-Si. As the laser radiation power is increased, the half-width of RS peak in the region of $\sim 520 \mathrm{~cm}^{-1}$ goes down and the peak form becomes more symmetric. This indicates increase of nanocrystallites sizes and decrease of $\alpha-\mathrm{Si}$ portion in the quartz/Si structure.

Shown in Figs. $4 \mathrm{a}$, and $4 \mathrm{~b}$ are the RS spectra of the initial silicon films on a glass substrate (Fig. 4, curve 1) and those after action of laser radiation of various power (Fig. 4, curves 2-4). One can see that, contrary to the quartz/Si structures, the RS spectra of initial glass/Si structures have two bands, 480 and $\sim 520 \mathrm{~cm}^{-1}$. This indicates that a silicon film on glass has inhomogeneous phase composition and involves both $\alpha-\mathrm{Si}$ and poly-Si phases $[1,4]$. Similarly to the case of the quartz/Si structures, a small decrease of the $\sim 520 \mathrm{~cm}^{-1}$ band halfwidth and a decrease of the $\sim 480 \mathrm{~cm}^{-1}$ band intensity are observed in the glass/Si structures as the laser radiation power grows. This indicates an increase of the silicon portion in the nanocrystalline phase.

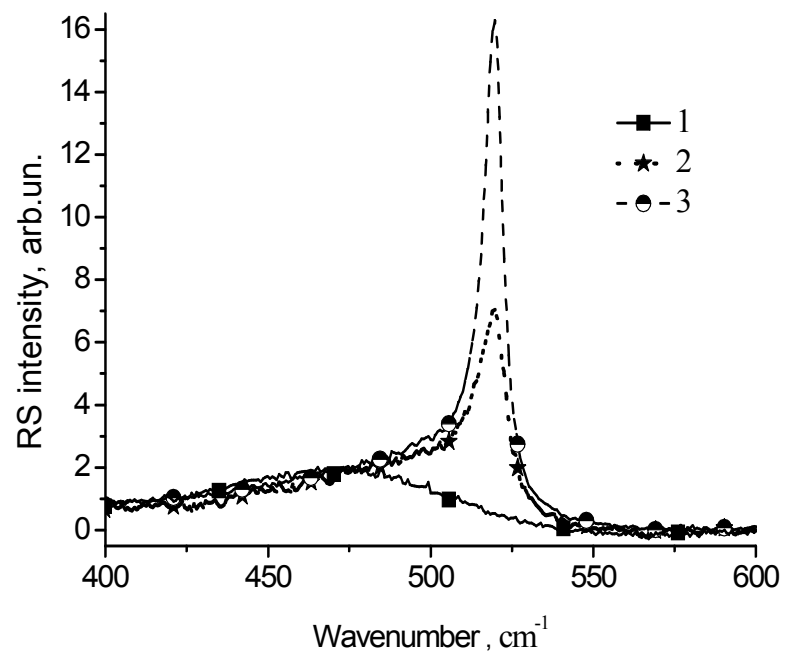

Fig. 3. RS spectra of silicon films on a quartz substrate before (curve 1) and after laser annealing (curves 2 and 3). Laser radiation power: $2-60 \mathrm{~W}, 3-80 \mathrm{~W}$; scanning rate of $5 \mathrm{~mm} / \mathrm{s}$. RS spectra of the specimens subjected to laser annealing are normalized to intensity of the $480 \mathrm{~cm}^{-1}$ line [11]. 

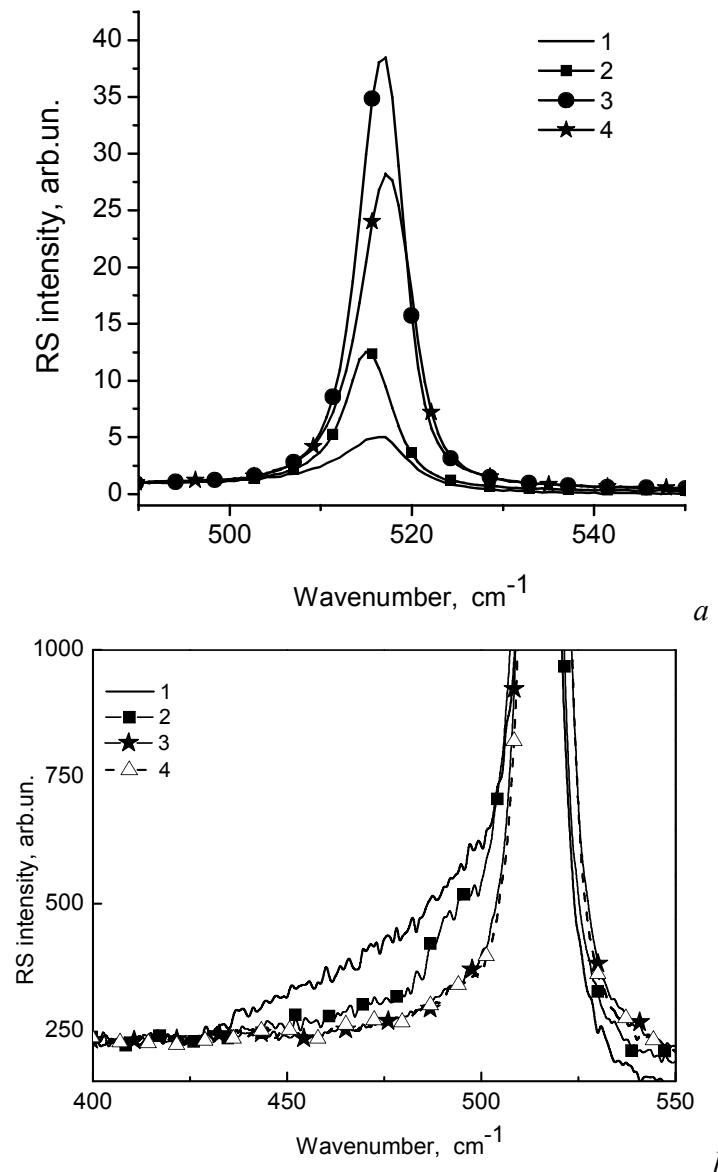

Fig. 4. RS spectra of silicon films on a glass substrate before (curve 1) and after laser annealing (curves 2-4). Laser radiation power: $2-50 \mathrm{~W}, 3-70 \mathrm{~W}, 4-80 \mathrm{~W}$; scanning rate of $5 \mathrm{~mm} / \mathrm{s}$. RS spectra of the specimens subjected to laser treatment are normalized to intensity of the $480 \mathrm{~cm}^{-1}$ line (a) or $520 \mathrm{~cm}^{-1}$ line (b) [11].

An analysis of RS spectra of the quartz/Si and glass/Si structures [9-11] showed that in both cases increase of the laser radiation power leads to intensity increase for the RS line $\sim 520 \mathrm{~cm}^{-1}$. This indicates growth of the portion of nanocrystalline silicon in the structure as the laser radiation power increases. The nonmonotonic dependence of relative intensity of the RS line $\sim 520 \mathrm{~cm}^{-1}$ on laser radiation power for the quartz/Si and glass $/ \mathrm{Si}$ structures can be explained within the critical action model proposed in $[1,4]$. The latter is based on the assumption that a phase transition from $\alpha$ Si to poly-Si occurs under action of laser radiation.

The above phase transition depends substantially on which part of the laser beam energy is absorbed in the specimen. There are three main regimes of crystal growth, corresponding to partial, almost complete and complete melting, respectively. Due to the effects of surface reflection, only a part of radiation is absorbed and turns into heat at laser irradiation of silicon surface. The temperature of a thin film is growing proportionally to the amount of absorbed energy of laser radiation. The film is melting to the liquid state as the $\alpha$-Si melting temperature is attained. After irradiation, the melt is cooling and solidifies in a polycrystalline phase. Formation of crystallites and growth of crystalline grains after laser annealing lead to reduction of absorption coefficient in the poly-Si layer [1]. As a result, temperature in the layer decreases, that, in its turn, leads to reduction of both recrystallization rate [4] and silicon layer transmission $[1,4]$. The optimal values of laser radiation power at which crystallization of $\alpha$-Si films occurs lie in a very narrow energy range between the partial melting regime and that of almost complete melting - the so-called critical action [1]. The value of critical action of laser radiation determined from optical transmission spectra for the quartz/Si, glass/Si, quartz $/ \mathrm{Si} / \mathrm{SiO}_{2}$ and $\mathrm{SiC} / \mathrm{Si} / \mathrm{SiO}_{2}$ structures is $\sim 60 \mathrm{~W}$.

The multilayer glass $/ \mathrm{Si}_{3} \mathrm{~N}_{4} / \mathrm{Si} / \mathrm{SiO}_{2}$ structures are of particular interest for practical application. Fig. 5 presents transmission spectra of the glass $/ \mathrm{Si}_{3} \mathrm{~N}_{4} / \mathrm{Si} / \mathrm{SiO}_{2}$ structures taken before laser annealing (curve 1) absorption edge is $\sim 3 \mathrm{eV}$ and after laser annealing (curve 2) - absorption edge is $\sim 3.4 \mathrm{eV}$. One can see that laser annealing leads not only to shifting of absorption edge towards shorter wavelengths but also to appearance of a broad transmission band in the 400-500 $\mathrm{nm}$ region.

According to [12], variation of excess silicon concentration in silicon nitride leads to a change in the bandgap width. By varying Si concentration, one can vary silicon nitride bandgap width over the $\sim 1.6-3.4 \mathrm{eV}$ region [12]. An increase of silicon content in silicon nitride films leads to shifting of absorption edge to the red spectral region. One can see from Fig. 5 that an insignificant decrease of absorption is observed for the treated structure in the $1.6-2.1 \mathrm{eV}$ region, and an additional band appears in the transmission spectrum in the $450-500 \mathrm{~nm}(2.7-2.4 \mathrm{eV})$ region.

One of the factors that explain variations in transmission spectrum of the glass $/ \mathrm{Si}_{3} \mathrm{~N}_{4} / \mathrm{Si} / \mathrm{SiO}_{2}$ structure is a decrease of absorption at $>2 \mathrm{eV}$ (below $600 \mathrm{~nm}$ ) because of formation of silicon nanocrystallites in a thin $\alpha$-Si layer in the course of laser annealing. According to [4], laser annealing can lead to phase transition from $\alpha-\mathrm{Si}$ to poly-Si. In this case, shifting of the absorption edge of silicon film to high-energy (blue) spectral region is observed. An assumption of silicon layer recrystallization under action of laser radiation is supported by the data of XRD studies. It was shown in [9] that XRD pattern of the glass $/ \mathrm{Si}_{3} \mathrm{~N}_{4} / \mathrm{Si} / \mathrm{SiO}_{2}$ structure treated with laser radiation has peaks corresponding to poly-Si. At the same time, XRD pattern of the initial specimen has no peaks corresponding to crystalline objects.

The transmission coefficient increase in the glass $/ \mathrm{Si}_{3} \mathrm{~N}_{4} / \mathrm{Si} / \mathrm{SiO}_{2}$ structure may be also caused by decrease of silicon film thickness due to the fact that silicon is partially solved in the oxide layer under laser annealing [4]. Besides, silicon concentration in the silicon nitride film may go down under action of laser radiation because of silicon diffusion. According to [10], this leads to shifting of absorption edge in the $\mathrm{SiN}_{\mathrm{x}}$ films to the blue spectral region. 


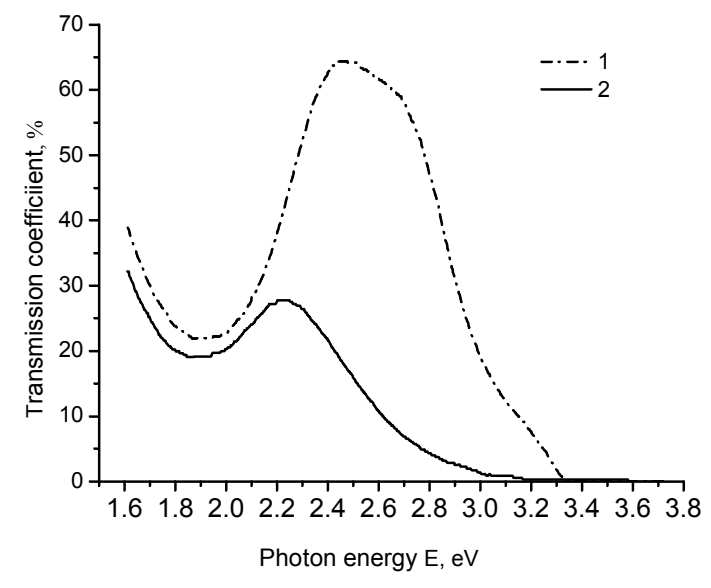

Fig. 5. Transmission spectra of the glass $/ \mathrm{Si}_{3} \mathrm{~N}_{4} / \mathrm{Si} / \mathrm{SiO}_{2}$ multilayer system: 1 - initial specimen, 2 - after laser treatment [9].

It was shown in [13] that an additional factor affecting transmission of the glass $/ \mathrm{Si}_{3} \mathrm{~N}_{4} / \mathrm{Si} / \mathrm{SiO}_{2}$ structure is variation of thickness of the silicon oxynitride $\left(\mathrm{SiN}_{\mathrm{x}} \mathrm{O}_{\mathrm{y}}\right)$ transition layer and formation of a $\mathrm{Si}_{3} \mathrm{~N}_{4}$ stoichiometric layer under laser annealing.

\section{Conclusion}

It is found experimentally for structures with thin silicon layers on various substrates as well as in quartz $/ \mathrm{Si} / \mathrm{SiO}_{2}$, $\mathrm{SiC} / \mathrm{Si} / \mathrm{SiO}_{2}$ and glass $/ \mathrm{Si}_{3} \mathrm{~N}_{4} / \mathrm{Si} / \mathrm{SiO}_{2}$ multilayer structures subjected to laser annealing that their optical transmission increases as laser radiation power grows to $60 \mathrm{~W}$. Further increase of laser radiation power results in reduction of optical transmission coefficients for all the above structures. An analysis of data on RS and optical transmission showed that effect of laser irradiation on structures with thin silicon layers leads to a phase transition (from $\alpha$-Si to nano-Si) in the silicon film. To explain the experimental data obtained, the critical action model can be applied. (That model has been developed for structures with layers of $\alpha-\mathrm{Si}$ or poly-Si deposited onto a single crystalline $\mathrm{Si}$ substrate.) The critical action value for the structures studied is $\sim 60 \mathrm{~W}$.

\section{Acknowledgements}

The author is indebted to Dr. Sci. Prof. V.P. Kladko and Dr. Sci. V.V. Strelchuk for their interest in this work and valuable discussions.

\section{References}

1. Zhijun Yuan, Qihong Lou, Jun Zhou, Jingxing Dong, Yunrong Wei, Zhijiang Wang, Hongming Zhao, Guohua $\mathrm{Wu}$, Numerical and experimental analysis on green laser crystallization of amorphous silicon thin films // Optics \& Laser Technology, 41(4), p. 380-383 (2009).
2. V.A. Karachinov, Effects of charge instability in a silicon carbide-dielectric system // Fizika Tekhnika Poluprov. 31(1), p. 53-55 (1997), in Russian.

3. G.K. Safaraliev, Yu.N. Emirov, M.K. Kurbanov, B.A. Bilalov, Spectral shift of photoluminescence bands of the $(\mathrm{SiC})_{1-\mathrm{x}}(\mathrm{AlN})_{\mathrm{x}}$ epitaxial films due to laser annealing // Semiconductors, 34(8), p. 891894 (2000).

4. T. Arguirov, T. Mchedlidze, V.D. Akhmetov, S. Kouteva-Arguirova, M. Kittler, R. Rölver, B. Berghoff, M. Först, D.L. Bätzner, B. Spangenberg, Effect of laser annealing on crystallinity of the $\mathrm{Si}$ layers in $\mathrm{Si} / \mathrm{SiO}_{2}$ multiple quantum wells // Appl. Surf. Sci. 254, p 1083-1086 (2007).

5. A.A. Vasenkov, Yu.H. Guketlev, A.G. Garitsyn, V.V. Fedorenko, Laserography - the basis of promising manufacturing technologies for VLSI // Elektronnaya Promyshlennost', no 6, p. 3-16 (1991), in Russian.

6. O.M. Zhigalina, D.N. Khmelenin, K.A. Vorotilov, A.S. Sigov, I.G. Lebo, Electron microscopy of the barium strontium titanate film structure on Pt-Ti$\mathrm{SiO}_{2}-\mathrm{Si}$ substrates after laser annealing // Physics of the Solid State, 51(7), p. 1482-1484 (2009).

7. S.P. Malyukov, G.V. Kalashnikov, V.V. Ptashnik, On an approach to application of laser technologies in production of solar cells // Izvestiya YuFU. Tekhnicheskie Nauki, no 12, p. 134-142 (2010), in Russian.

8. V.N. Lissotschenko, R.V. Konakova, B.G. Konoplev, V.V. Kushnir, O.B. Okhrimenko, A.M. Svetlichnyi, Reduction in absorption in quartz/Si, quartz/Si $/ \mathrm{SiO}_{2}$, and $\mathrm{SiC} / \mathrm{Si} / \mathrm{SiO}_{2}$ structures on laser treatment // Semiconductors, 44(3), p. 309-312 (2010).

9. R.V. Konakova, V.P. Kladko, O.S. Lytvyn, O.B. Okhrimenko, B.G. Konoplev, A.M. Svetlichnyi, V.N. Lissotschenko, Modification of properties of the glass $-\mathrm{Si}_{3} \mathrm{~N}_{4}-\mathrm{Si}-\mathrm{SiO}_{2}$ structure at laser treatment // Semiconductor Physics, Quantum Electronics \& Optoelectronics, 12(3), p. 284-286 (2009).

10. E.Yu. Volkov, V.N. Lissotschenko, R.V. Konakova, O.B. Okhrimenko, A.M. Svetlichnyi, Effect of laser treatment on the properties of amorphous silicon films // Izvestiya Vuzov. Fizika, 54(1/2), p. 143-146 (2011), in Russian.

11. R.V. Konakova, A.F. Kolomys, O.B. Okhrimenko, V.V. Strelchuk, A.M. Svetlichnyi, M.N. Grigoriev, B.G. Konoplev, Laser-annealing-induced features of the Raman spectra of quartz/Si and glass/Si structures // Semiconductors, 48(5), p. 621-624 (2014).

12. M.D. Efremov, V.A. Volodin, D.V. Marin, S.A. Arzhannikova, G.N. Kamaev, S.A. Kochubei, A.A. Popov, Variation in optical-absorption edge in $\mathrm{SiN}_{\mathrm{x}}$ layers with silicon clusters // Semiconductors, 42(2), p. 202-208 (2008).

13. A.P. Baraban, D.V. Egorov, A.Yu. Askinazi, L.V. Miloglyadova, Electroluminescence of $\mathrm{Si}-$ $\mathrm{SiO}_{2}-\mathrm{Si}_{3} \mathrm{~N}_{4}$ structures //Techn. Phys. Lett. 28(12), p. $978-981$ (2002). 